\title{
STUDI PENGARUH PARAMETER PEMOTONGAN TERHADAP KEKASARAN PERMUKAAN PADA PROSES UP DAN DOWN MILLING DENGAN PENDEKATAN VERTICAL MILLING
}

\author{
Muh Alfatih Hendrawan \\ Jurusan Teknik Mesin Universitas Muhammadiyah Surakarta \\ J1. A Yani Pabelan Kartasura Surakarta 57102 \\ Email: alfatih@ums.ac.id
}

\begin{abstract}
ABSTRAK
Salah satu kualitas dari proses pemotongan logam adalah kekasaran permukaan hasil pemotongan. Kekasaran hasil pemotongan pada horizontal milling banyak dipengaruhi oleh proses yang terjadi selama pemotongan. Penelitian ini bertujuan untuk mengetahui pengaruh proses pemotongan; kedalaman pemotongan, kecepatan pemakanan, kecepatan pemotongan, terhadap kekasaran permukaan. Rancangan percobaan yang digunakan adalah menggunakan metode factorial design $2^{3}$. Dari eksperimen yang telah dilakukan diperoleh kesimpulan bahwa kecepatan pemakanan mempunyai pengaruh positif terhadap peningkatan kekasaran permukaan, sedangkan kecepatan potong mempunyai pengaruh negatif.
\end{abstract}

Kata Kunci: kekasaran, milling, factorial design

\section{PENDAHULUAN}

Untuk membuat suatu produk yang berkualitas tentunya harus didukung oleh proses pemesinan yang baik. Setiap proses pemesinan mempunyai ciri tertentu atas permukaan benda kerja yang dihasilkan, salah satunya adalah kekasaran permukaan. Hal ini terjadi karena pada proses pemesinan sering terjadi penyimpanganpenyimpangan yang disebabkan oleh kondisi pemotongan dan kekakuan mesin.

Untuk mengatasi hal tersebut, maka diadakan percobaan untuk menganalisis pengaruh kondisi pemotongan seperti kedalaman potong, kecepatan pemakanan dan kecepatan potong terhadap kekasaran permukaan pada proses freis tegak dengan tinjauan proses down dan up milling.

Adapun didalam beberapa penelitian yang telah dilakukan dianjurkan bahwa bentuk hubungan kekasaran permukaan dan kondisi pemotongan adalah dalam bentuk sebagai berikut:

$$
\mathrm{SR}=\mathrm{C} \cdot \mathrm{V}_{\mathrm{c}}{ }^{\mathrm{p}} \cdot \mathrm{V}_{\mathrm{f}}^{\mathrm{q}} \cdot \mathrm{d}^{\mathrm{r}}
$$

Dimana SR adalah kekasaran permukaan $(\mu \mathrm{m})$, $\mathrm{C}$ adalah konstanta, $\mathrm{V}_{\mathrm{c}}$ adalah kecepatan potong (m/menit), $\mathrm{V}_{\mathrm{f}}$ adalah kecepatan pemakanan ( $\mathrm{mm} / \mathrm{menit})$ dan d adalah ketebalan pemotongan (mm).

Tujuan penelitian yaitu mengetahui pengaruh kecepatan potong, kecepatan pemakanan dan kedalaman pemotongan terhadap kekasaran permukaan pada proses freis tegak. Tujuan yang kedua adalah membandingkan kekasaran permukaan benda kerja hasil proses up milling dan 
down milling. Tujuan ketiga adalah menentukan persamaan regresi kekasaran permukaan terhadap parameter pemotongan.

\section{TINJAUAN PUSTAKA}

\section{Proses pemotongan up milling dan down milling}

Berbeda dengan pemesinan yang lain, proses mengefrais tidak menghasilkan geram dengan tebal yang tetap melainkan berbentuk koma dengan tebal geram yang beaibah. Tebal geram tersebut dipengaruhi oleh gerak makan pergigi $\left(f_{z}\right)$ dan sudut posisi (f) yang pada setiap saat berubah harganya karena perubahan posisi mata potong (gigi pahat frais). Gambar 1 menunjukkan perubahan tebal geram sebelum terpotong (h) untuk proses mengefrais datar dan tegak.

\section{Gambar 1. Perubahan Tebal Geram pada Proses Frais}

\section{Hubungan kekasaran permukaan dengan parameter potong}

Proses milling adalah suatu proses permesinan yang faktor utamanya adalah gesekan antara pahat dengan benda kerja. Selama proses milling akan terjadi bebcrapa gerakan yang saling berkaitan. Gerakan ini dapat diatur berdasarkan parameter pemctongan. Parameter yang diteliti adalah kecepatan potong ( $\mathrm{Vc}$ ), kecepatan pemakanan (Vf), dan ketebalan potong (a). Hubungan ketiga parameter tersebut dengan kekasaran permukaan (SR) yang dihasilkan dapat dimodelkan sebagai berikut :

$$
S R=f\left(V_{c}, V_{f}, a\right)
$$

Dengan pemodelan diatas, maka diketahui bahwa kekasaran permukaan merupakan fungsi dari ketiga parameter pemotongan. Untuk mempermudah dalam meneliti hasil-hasil yang diperoleh, maka persamaan diatas dapat dikembangkan menjadi sebagai berikut :

$$
\mathrm{SR}=\mathrm{C} \cdot \mathrm{V}_{\mathrm{c}} \mathrm{p}, \mathrm{V}_{\mathrm{f}} \cdot \mathrm{q} \cdot a \cdot \mathrm{r}
$$

dimana:

SR = Harga kekasaranpermukaan

$\mathrm{V}_{\mathrm{c}} \quad=$ Kecepatan potong

$\mathrm{V}_{\mathrm{f}}^{\mathrm{c}} \quad=$ Kecepatan pemakanan

a = ketebalan potong

$\mathrm{p}, \mathrm{q}, \mathrm{r}=$ Konstanta percobaan

SR (Surface Roughness) adalah variabel tidak bebas (respon) dan model persamaan fungsional pada persamaan sebelumnya dapat diubah menjadi bentuk logaritma linear sebagai berikut :

$$
\begin{aligned}
& \log S R=\log C+p \log V_{c} \\
& +q \log V_{f}+r \log a
\end{aligned}
$$

\section{Kekasaran permukaan}

Sifat permukaan benda kerja hasil proses pemesinan terdiri dari dua kriteria yaitu kekasaran permukaan dan kerataan permukaan. Diantara dua elemen tersebut kekasaran permukaan adalah suatu sifat yang dapat dirasakan halus atau kasar. Pada setiap proses pemesinan dihasilkan suatu garus bentuk. Garis bentuk yang terjadi tersebut mempunyai ciri-ciri tersendiri tergantung dari mata potong peralatan yang dipakai. Tetapi semuanya mengarah pada suatu pola yaitu puncak dan lembah. Garis bentuk yang diperlihatkan oleh irisan tegak lurus terhadap permukaan inilah yang dinamakan kurva kekasaran. Pada irisan ini dapat dilihat adanya gelombang yang mempunyai jarak horisontalnya (antara puncah dan lembah) lebih panjang daripada jarah vertikalnya (antara puncak dengan lembah). Jika fokus penginderaan dipertajam, maka akan terlihat kurva kekasaran. 


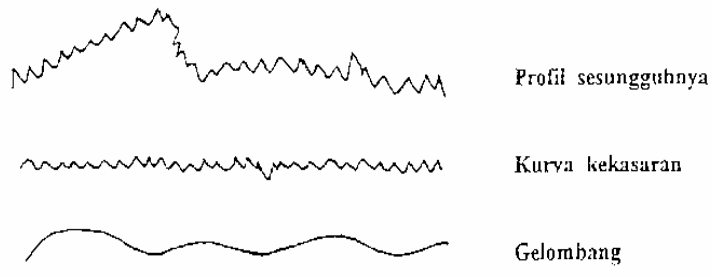

\section{Gambar 2. Profil Kurva Kekasaran Permukaan}

Harga kekasaran permukaan dari benda kerja dapat dideteksi dengan meneliti garis pusat rata-rata $\left(R_{a}\right)$ dan juga jarak puncak tertinggi dengan lembah terdalam $\left(R_{t}\right)$. Dari beberapa cara untuk menentukan kekasaran permukaan, metode garis pusat rata-rata dapat digunakan untuk menaksir dan menyatakan kekasaran untuk panjang $(I)$ sejauh garis pusat. Kurva garis center dapat dinyatakan secara matematis yaitu :

$$
\mathrm{Y}=\mathrm{f}(\mathrm{x})
$$

Dimana garis pusat tersebut dinyatakan sebagai sumbux dan besaran vertikal sebagai sumbu y,

\begin{tabular}{|c|c|c|c|c|c|}
\hline $\begin{array}{c}\text { Kec.Potong } \\
(\mathrm{m} / \mathrm{min})\end{array}$ & $\begin{array}{l}\text { Kec.makan } \\
\text { sehing } \\
\text { mmming }\end{array}$ & al & $R_{a}$ & $\begin{array}{l}\text { otong } \\
\text { pate } \\
\text { pa2 }\end{array}$ & (mm) \\
\hline $\mathrm{Vc1}$ & Vf1 & & & & \\
\hline & $\mathrm{Vf} 2$ & 1 & & & \\
\hline $\mathrm{Vc} 2$ & Vf1 & $\bar{l}$ & & & \\
\hline & Vf2 & & & & \\
\hline
\end{tabular}

Pada gambar 3 jumlah luasan diatas dan dibawah garis pusat adalah besar, jika luasan tersebut dinyatakan sebagai A, maka akan didapat :

$$
\int_{0}^{l} f(x) d x=A \int_{0}^{l} f(x) d x=A
$$

Sehingga nilai Ra menjadi :

$$
R a=\frac{A}{l} R a=\frac{A}{l}
$$

Ukuran $\mathrm{R}_{\mathrm{t}}$ adalah jarak puncak tertinggi dengan lembah terdalam (paling rendah), jika gelombang (kuva kekasaran) dalam bentuk sebenarnya kecil, maka nilai $\mathrm{R}_{\mathrm{t}}$ dapat dinyatakan dengan $\mathrm{R}_{\text {maks }}$ atau tinggi maksimum.

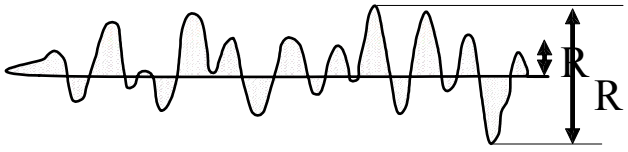

Gambar 3. Garis Pusat Rata-rata dan Tinggi Maksimum Kekasaran Permukaan

Pada umumnya kekasaran permukaan disimbulkan hanya dengan nilai $\mathrm{R}_{\mathrm{a}}$, ini dikarenakan harga rata-rata cukup mewakili kekasaran sesungguhnya.

\section{METODOLOGI PENELITIAN}

\section{Bahan dan Alat}

- Peralalatan yang digunakan pada penelitian adalah mesin milling EMCO MAXIMAT SUPER 11 dengan kemampuan feed rate $0,003-0,30 \mathrm{~mm} /$ putaran dan putaran mesin $120-2000 \mathrm{rpm}$.

- Material yang digunakan pada percobaan adalah SS42 dengan kekerasan $80 \mathrm{HB}$, dengan dimensi panjang $24 \mathrm{~mm}$, lebar 10 mm dan tinggi $10 \mathrm{~mm}$.

- pahat yang dipakai dalam penelitian ini adalah pahat End Mill HSSA1 dengan diameter $\mathrm{f}$ $14 \mathrm{~mm}$ dan jumlah gigi sebanyak 4 .

- Perencanaan eksperimen yang akan dilakukan adalah sebagai berikut:

a. respon yang akan dicari adalah kekasaran permukaan $(\mathrm{mm})$ atau bisa disebut variabel dependen.

b. variabel independen atau dapat disebut predictor adalah kecepatan potong $\left(\mathrm{V}_{\mathrm{c}}\right)$, kecepatan makan $\left(\mathrm{V}_{\mathrm{f}}\right)$ dan kedalaman pemotongan (a).

c. replikasi pada setiap pengambilan data adalah dua kali

d. Model eksperimen adalah sebagaimana pada Tabel 1.

Tabel 1. Rancangan Percobaan 
Keterangan :

$\mathrm{V}_{\mathrm{cl}}=$ kecepatan potong $1=5,28 \mathrm{~m} / \mathrm{min}$

$\mathrm{V}_{\mathrm{c} 2}=$ kecepatan potong $2=16,27 \mathrm{~m} / \mathrm{min}$

$\mathrm{V}_{\mathrm{fl}}^{\mathrm{c} 2}=$ kecepatan pemakanan $1=14,4 \mathrm{~mm} / \mathrm{min}$

$\mathrm{V}_{\mathrm{f} 2}=$ kecepatan pemakanan $2=222 \mathrm{~mm} / \mathrm{min}$

$\mathrm{a}_{1}=$ kedalaman potong $1=0,5 \mathrm{~mm}$

$\mathrm{a}_{2}=$ kedalaman potong $2=1 \mathrm{~mm}$

- Proses pemesinan yang dilakukan adalah pendekatan proses up milling dan down pada mesin milling vertikal. (lihat Gambar 4 dan 5)

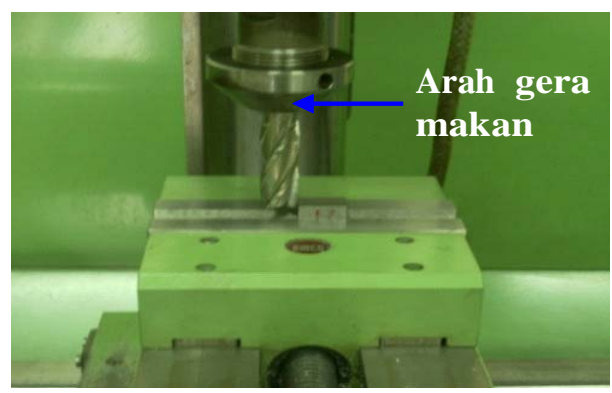

Gambar 4. Proses up milling

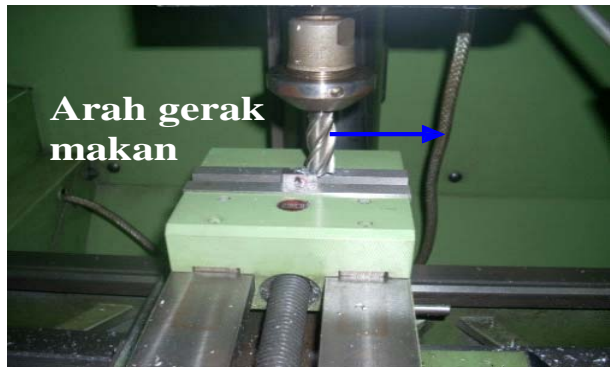

Gambar 5. Proses down Milling

- Pengukuran kekasaran permukaan dengan menggunakan alat ukur SURFTEST 401 Series 178 dan posisi pengukuran adalah ditunjukkan pada Gambar 7 dan 8 .

Gambar 6. Alat Ukur SURFTEST 401

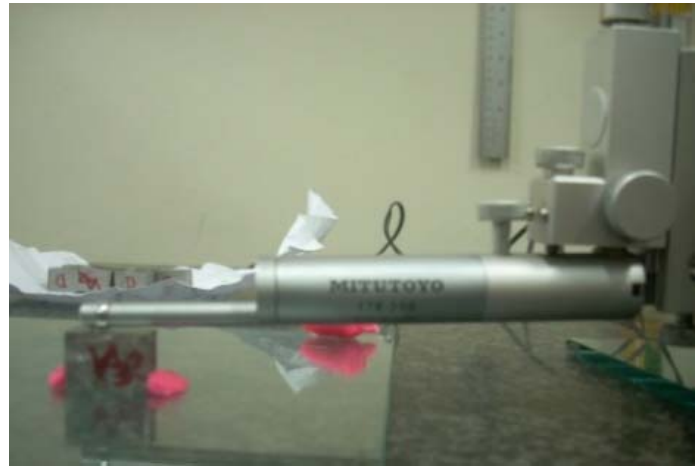

Gambar 7. Posisi Pengukuran Kekasaran Permukaan

\section{HASIL DAN PEMBAHASAN}

Pengaruh parameter pemotongan terhadap kekasaran permukaan hasil proses milling up dan down dapat dilihat pada grafik-grafik berikut.

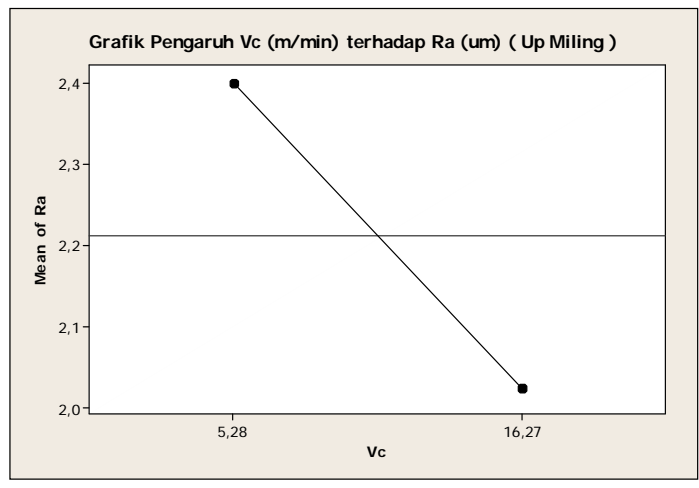

\section{Gambar 8. Grafik Pengaruh Rata-rata} Ra vs $\mathrm{V}_{\mathrm{c}}$ pada Proses up Milling

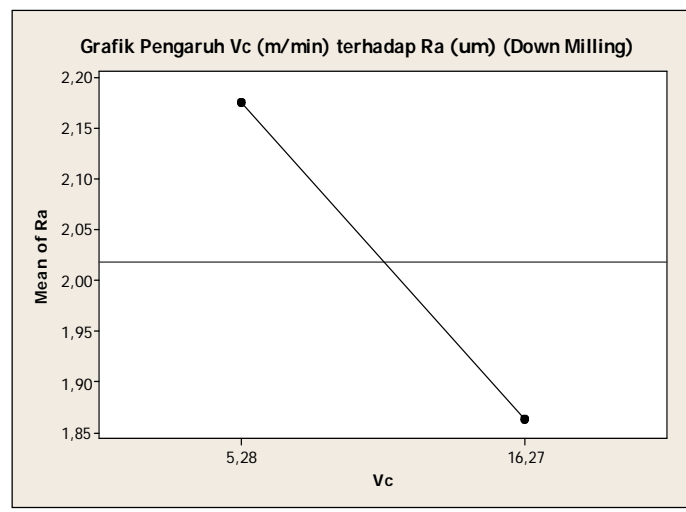

Gambar 9. Grafik Pengaruh Rata-rata Ra vs $V_{c}$ pada Proses down Milling 
Dari Gambar 8 dan 9 terlihat baik pada proses up maupun down milling mempunyai pengaruh yang negatif terhadap kekasaran permukaan, artinya bahwa semakin besar kecepatan potong maka semakin kecil kekasaran permukaan yang dihasilkan. Jika dibandingkan antaraproses upmilling dengandown milling terlihat bahwa pada kecepatan yang sama maka kekasaran yang terjadi lebih besar pada up milling. Hal ini dikarenakan ada upmilling terjadi proses getaran yang lebih besar dibandingkan dengan downmilling.

Pada Gambar 10 dan 11 dapat dianalisis bahwa kecepatan pemakanan $\mathrm{V}_{\mathrm{f}}$ mempunyai pengaruh positif terhadap kekasaran permukaan, artinya semakin besar kecepatan pemakanan maka semakin besar pula kekasaran permukaan benda kerja hasil proses milling. Jika dibandingkan antara kedua proses milling maka up milling lebih menghasilkan kekasaran permukaan yang lebih besar dibandingkan proses down milling, hal ini dapat dilihat pada kecepatan pemakanan yang sama proses milling jenis up menghasilkan kekasaran yang lebih tinggi.

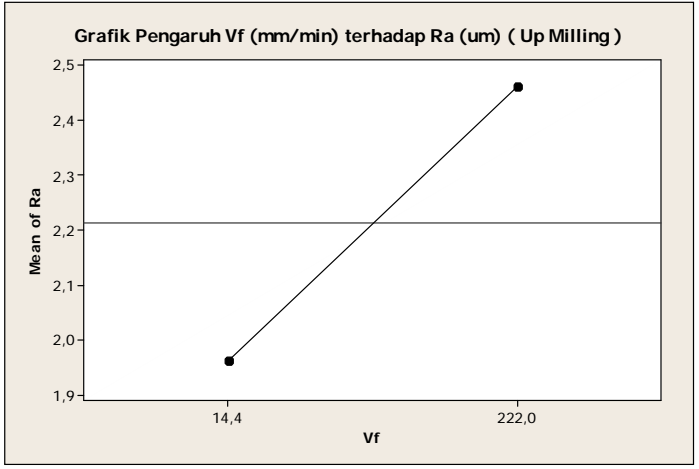

\section{Gambar 10. Grafik Pengaruh Rata-rata Ra vs $V_{f}$ pada Proses up Milling}

Kedua gambar yaitu Gambar 12 dan 13 menunjukkan bahwa kedalaman potong $a$ mempunyai pengaruh yang positif terhadap kekasaran permukaaan benda kerja, artinya bahwa semakin besar kedalaman potong maka semakin besar pula kekasaran permukaan benda kerja hasil pemotongan. Kekasaran permukaan hasil proses up milling pada kedalaman potong yang sama lebih besar jika dibandingkan dengan proses milling jenis down.

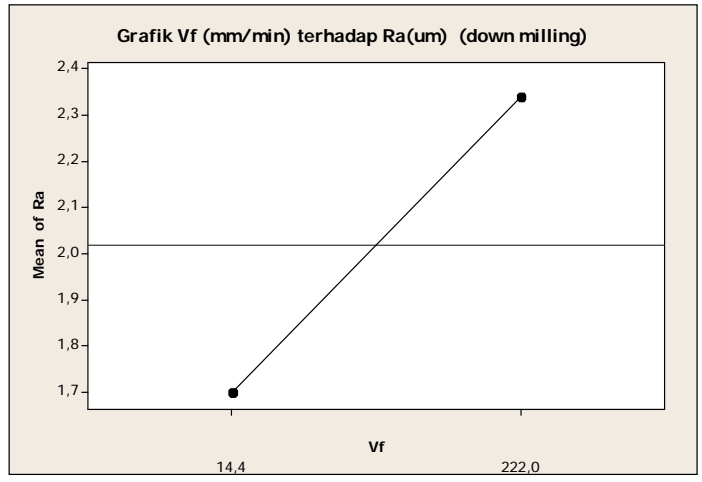

\section{Gambar 11. Grafik Pengaruh Rata-rata Ra vs $V_{f}$ pada Proses down Milling}

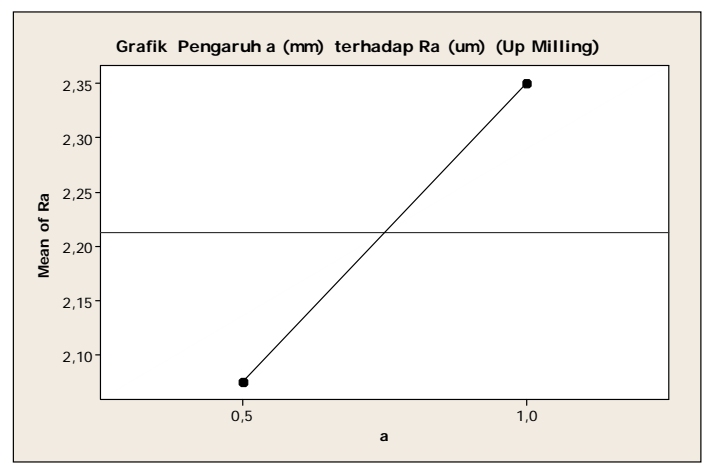

Gambar 12. Grafik Pengaruh Rata-rata Ra vs a pada Proses up Milling

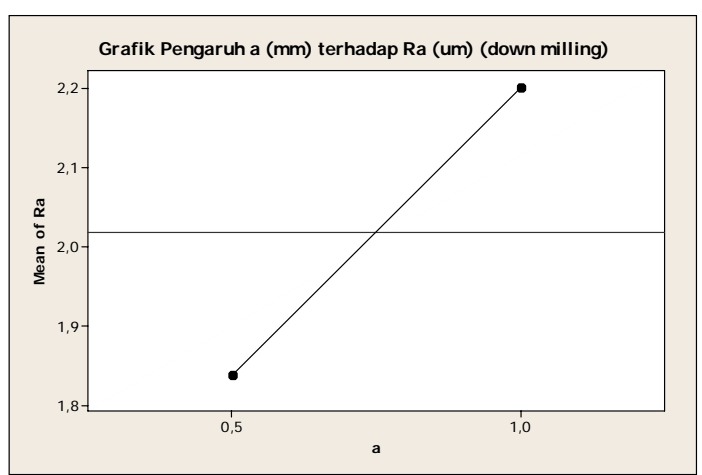

Gambar 13. Grafik Pengaruh Rata-rata Ra vs a pada Proses up Milling

\section{KESIMPULAN}

Dari pengamatan yang telah dilakukan maka dapat disimpulkan sebagai berikut :

1. Kecepatan potong $\left(\mathrm{V}_{c}\right)$, kecepatan pemakanan $\left(\mathrm{V}_{\mathrm{f}}\right)$ dan kedalaman pemotongan (a) 
mempunyai pengaruh terhadap kekasaran permukaan benda kerja hasil proses milling.

2. Kedalaman pemotongan dan kecepatan pemakanan mempunyai pengaruh yang positif terhadap kekasaran permukaan, sedangkan kecepatan potong berpengaruh negatif.

3. Proses down milling menghasilkan permukaan benda kerja lebih halus dari pada proses up milling.
4. Persamaan regresi untuk kekasaran permukaan yaitu:

proses down milling

$$
R_{a}=1,87 V_{c}^{-0,152} V_{f}^{0,120} a^{0,274}
$$

proses up milling

$$
R_{a}=2,36 V_{c}^{-0,161} \cdot V_{f}^{0,0,086} \cdot a^{0,20}
$$

\section{DAFTAR PUSTAKA}

Anonimus, SURFTEST 401 series 178 Manual Book, Mitutoyo.

Iriawan, Nur, Astuti, Septin Puji, Mengolah Data Statistik dengan Mudah Menggunakan

Minitab 14,Andi Offset, Yogyakarta, 2006

Kalpakjian, Serope, Steven R. Schmid, Manufacturing Engineering and Technology, fourth edition, Addison Wesley, India, 2000

Rochim, Taufiq, Teori dan Teknologi Proses Pemesinan, Laboratorium Teknik Produksi, FTI, Institut Teknologi Bandung, 1993 